\title{
Floresta Atlântica. Estudo para o desenvolvimento sustentável
}

\author{
CRistina Gerber Jõ̃o* \\ BRUnO HaRmuth KopiTTKE** \\ CARlos Loch**** \\ JAMIR SPERANDIO****
}

\section{RESUMO}

A Floresta Tropical Atlântica representa o maior remanescente florestal do Estado de Santa Catarina. Observa-se, entretanto, um incremento no índice de desmatamento, tendo como resposta governamental, exigências de se manejar sustentadamente os recursos florestais. Este trabalho pretende lembrar que no processo decisório o manejo de rendimento sustentado pode ou não ser atrativo. Conclui-se que o modelo atual de sustentabilidade falha ao tentar promover o local, com clareza de objetivos, afirmando-se que aqueles que geram benefícios ambientais não devem assumir sozinhos os custos desta produção.

Palavras-chave: manejo florestal, política ambiental, economia ecológica, análise custo/benefício.

\section{ABSTRACT}

ATLANTIC TROPICAL FOREST. A study for sustainable development . The tropical Atlantic Forest represents the biggest remaining of the Santa Catarina state forest, although it is observed in the increasing index of deforest having as government response, an exigency of sustainable management of the forest resources. This paper wants to remember that in the decision process the management of the sustainable income may not be attractive. It is concluded that the today's sustainable model lacks when tries to promote the localized, with clear objectives, assuming that those which generates environment benefits shall not assume the costs of this production itself.

Key-words: Forest management, environment policy, ecological economics, cost/benefit analysis.

\footnotetext{
*Eng.Florestal, MSc, pós-graduando do Curso de Pós-Graduação em Eng. de Produção, UFSC.

*** Eng. Industrial, Dr., professor do Curso de Pós-Graduação em Engenharia de Produção, UFSC.

**** Eng. Florestal, Dr., professor do Curso de Pós-Graduação em Engenharia de Produção, UFSC

${ }^{* * * *}$ Eng. Florestal, MSc, UFPR.
} 


\section{INTRODUÇÃO}

O Brasil, como muitos países em desenvolvimento, utiliza-se de uma política intervencionista no uso dos recursos naturais. Meio ambiente e desenvolvimento econômico estão cada vez mais associados no debate internacional sobre o futuro da humanidade pela riqueza e pela diversidade dos recursos biológicos, exigindo-se definições do nível de preservação dos ecossistemas naturais, com conseqüente ênfase governamental para proteger estes recursos. Observa-se entretanto um incremento no índice de desmatamento (SAA/AS, 1994), tendo como resposta governamental exigências de se manejar sustentadamente os recursos florestais na tentativa de manter esta cobertura, permitindo e fornecendo aos usuários destes produtos alguma renda.

Utilizando a Floresta Tropical Atlântica, área de abrangência do estado de Santa Catarina, como exemplo, procura-se comparar o modelo corrente de sustentabilidade dentro da atual política intervencionista como um modelo um tanto mais flexível.

Este trabalho propõe-se orientar o pesquisador desta que no processo decisório as técnicas de manejo sustentado podem ou não ser atrativas.

Em particular os responsáveis pela política ambiental devem confrontar as possibilidades e tornar uma floresta atrativa para os pequenos agricultores que dependeu economicamente do uso da terra, caso contrário ele transformará a área desta floresta em agricultura ou em pastagem, ou ainda, a venderá para que outros a façam.

O desmatamento no estado de Santa Catarina acarretou problemas econômicos (falta de lenha e madeira); problemas ecológicos (ausência de proteção do solo) e problemas sociais (pela perda da produtividade).

Inicia-se com uma visão global da Floresta Tropical Atlântica em Santa Catarina e o seu remanescente. Em seguida será feito um breve comentário sobre a legislação brasileira no que concerne ao uso de bens e serviços florestais. Por fim, será feita uma análise do atual modelo de sustentabilidade.

\section{A FLORESTA TROPICAL ATLÂNTICA}

As florestas tropicais são os ecossistemas que detém a maior diversidade de espécies dentre todas as demais florestas. É apontada como sendo uma das florestas ameaçadas de extinção (UNICAMP, 1991). A Floresta Tropical Atlântica, ou Floresta Atlântica representou 12\% do território nacional. A área desta floresta em Santa Catarina chegou a 29 mil km² (30\% da área do estado). Restam hoje 7,1 mil km² (7\% da área do estado). Fora os parques e reservas biológicas, restam hoje $5 \mathrm{mil} \mathrm{km}^{2}$ (5\% da área do estado). Vivem nesta área 60\% da população de Santa Catarina (FATMA, 1995).

Segundo KLEIN (1978), a Floresta Atlântica estende-se por toda a costa atlântica, nas planícies quaternárias correndo paralelamente ao oceano 
Atlântico, alargando-se no baixo vale do rio Itajaí-Açú até uma altitude de $800 \mathrm{~m}$, onde alcança uma penetração de $150 \mathrm{~km}$.

Um estudo do remanescente deste sistema biológico está sendo feito pela Fundação Estadual do Meio Ambiente - FATMA -, porém não publicado até a presente data.

Segundo UNICAMP (1991), cinqüenta por cento das árvores da Floresta Atlântica são endêmicas. Dentre palmeiras, bromélias e outras epífitas este índice chega a mais de setenta por cento. Entre o mamíferos trinta e nove por cento também são endêmicos, o mesmo ocorrendo com a maioria das borboletas, dos anfíbios e das aves nativas. Esta diversidade, ao mesmo tempo que representa uma excepcional riqueza de patrimônio genético e paisagístico, torna o ecossistema extremamente frágil. A destruição de parcelas desta floresta pode significar a perda irreversível de inúmeras espécies. É por esta razão que 171 das 202 espécies brasileiras consideradas em extinção são originárias da Floresta Atlântica. A ameaça também se dá ao patrimônio composto por conhecimentos sobre a floresta e seus ciclos, o valor de suas madeiras, fibras, folhas, frutos e uma grande variedade de plantas medicinais.

No sentido amplo do termo, Floresta Atlântica engloba um diversificado mosaico de ecossistemas florestais, com estruturas e composições florísticas bastante diferenciadas, acompanhando a diversidade de solos, relevos e características climáticas da região onde ocorre.

\section{A LEGISLAÇÃO AMBIENTAL}

A preocupação com a conservação dos recursos naturais pelo Governo Federal é antiga, data de 1934 com o primeiro Código Florestal Brasileiro. Este dita algumas regras sobre preservação de encostas com declividade acentuada. Em 1965, o novo Código Florestal - que vigora até hoje - estabelece as florestas como uso de bem de interesse comum do povo, limitando os direitos de propriedade. Porém só a partir de 1986 é que institui a exploração racional de florestas em regime de rendimentos sustentáveis (Lei 7511 de 07/07/86).

Em 1990 o governo transforma todo o complexo ecológico Floresta Atlântica em área de preservação permanente, não se podendo fazer dela uso para qualquer finalidade (decreto 99547 de 25/09/90). Em 1993 o Governo Federal retrocede e passa então a permitir a utilização da Floresta Tropical Atlântica através do manejo sustentado (decreto 750 de 10/02/93).

\section{A DEVASTAÇÃO DA FLORESTA ATLÂNTICA}

O desenvolvimento corrente na área rural da Floresta Atlântica em Santa Catarina se dá com uma mistura de livre comércio e intervenção governamental. O livre comércio, onde o agricultor é o proprietário da área e dela dispõe como melhor lhe aprouver, e a intervenção governamental, onde se insere uma rígida legislação que cria parques e reservas por força de decreto. 
A estratégia de sobrevivência de comunidades rurais existentes na Floresta Atlântica consiste na remoção da floresta e posterior utilização da área desmatada para agricultura ou pecuária. Mesmo as áreas onde o relevo apresenta $45^{\circ}$ de declividade ou até mais, são utilizadas para agricultura itinerante. Juntando-se à fragilidade do solo com altas taxas pluviométricas, estas lavouras apresentam produtividade apenas nos primeiros 2 ou 3 anos de cultivo, quando então novas áreas de floresta serão utilizadas. Com este procedimento as áreas devastadas aumentam com o passar dos anos.

$\mathrm{O}$ corte de madeira pouco contribui para o aumento da renda do agricultor, uma vez que não se observa o seu aproveitamento.

Com o rápido declínio da área florestal as autoridades ambientais demonstram um grande interesse em proteger os recursos naturais ali localizados e usam como instrumento a devastação da Floresta Atlântica em áreas de preservação permanente, proibindo sua utilização. Os agricultores sem alternativa de uso da terra aceleram o processo de desmatamento como forma de garantir seu meio de sobrevivência.

A instituição do regime de manejo sustentado trás consigo a esperança de um desenvolvimento sustentado nas áreas rurais da Floresta Tropical Atlântica. $\mathrm{O}$ manejo sustentado capacitaria o agricultor a obter a renda a partir do seu estoque de capital natural com base na produtividade inerente da floresta. Em outras palavras, manter o estoque da floresta em crescimento e retirar o incremento ocorrido de período em período. Mesmo que o manejo não mantenha a floresta virgem, mantém a cobertura florestal, protege a biodiversidade, bem como garante a manutenção das funções da floresta como provedora de bens e recursos naturais.

Em julho de 1999 ocorreu em São Paulo o I Seminário Nacional sobre Recursos Naturais da Floresta Atlântica, promovido pelo Conselho Nacional da Reserva da Biosfera da Floresta Atlântica, tendo como tema a produtividade da mesma, através de projetos de plantio e de manejo.

Segundo Clayton Lino, um dos diretores do Conselho, o problema fundiário é um dos responsáveis pela exploração insustentável de certas espécies nativas, que mesmo com legislação de proteção e com tecnologia de manejo, é difícil controlar o sustento da produção. A exploração desordenada reduziu até mesmo as matas de espécies que tinham grande abundância, como as matas de Araucária.

Carlos Novi, que trabalha no Vale do Ribeira (SP), diz que o problema é ainda maior pela falta de conhecimento sobre os mecanismos de recuperação. Afim de amenizar tal problema, ele tomou a iniciativa de fazer um levantamento minucioso da capacidade explorativa da região.

O Seminário concluiu que há urgência de se adotar políticas públicas que criem instrumentos legais, econômicos e de mercado para incentivar o desenvolvimento sustentável na Floresta Atlântica, que incluiriam a promoção da fiscalização, da educação ambiental, da organização e capacitação dos produtores. 


\section{O MANEJO SUSTENTADO EM FLORESTAS}

\section{Da viabilidade técnica e ecológica}

O método compreende as seguintes etapas:

- Estratificação tipológica e volumétrica, que consiste basicamente na definição e classificação das unidades florestais em um modelo mais homogêneo possível;

- Análise estrutural de maciços florestais, que permite uma profunda análise de maciços através de estruturas horizontais, verticais e paramétricas (HOSOKAWA, 1982):

a) A estrutura horizontal quantifica variáveis como densidade, dominância, frequiência e valor de importância das espécies que compõem a floresta;

b) A estrutura vertical abrange as características sociológicas das espécies e a dinâmica das populações;

c) A estrutura paramétrica estima quantitativamente parâmetros como diâmetro, altura, fator de forma, etc.

Consecução dos benefícios objetivados

Até aqui foram abordados aspectos puramente florestais. Para que a técnica de manejo florestal cumpra o princípio da sustentabilidade, a atividade florestal de proporcionar, além do equilíbrio econômico, a estabilidade ecológica e harmonização social.

A sua consecução pode ser efetivada mediante a aplicação de técnicas de pesquisa operacional, para tanto são necessários métodos quantitativos que estimem as variáveis econômicas, ecológicas e sociais da seguinte maneira:

a) Equilíbrio econômico - análise custo/benefício;

b) Harmonização social - equacionando-se a oferta contínua do volume de trabalho com a demanda do mercado de mão-de-obra;

c) Estabilidade ecológica - é o aspecto mais complexo a ser solucionado, uma vez que sua quantificação é extremamente difícil. Contudo, alguns trabalhos de pesquisa têm introduzido conceitos como valor, custo, benefício e risco ecológico (CENTRO DE PESQUISAS FLORESTAIS UFPR, 1981).

Estas conceituações permitem a formulação de métodos quantitativos, ainda que incipientes, baseados na produção de determinados benefícios ou riscos, bem como através da geração de custos substitutivos em função do diferencial de valor ecológico decorrente da geração ou ausência de floresta. As variáveis a serem estimadas, em princípio, são os efeitos da floresta sobre o clima, solos, água, poluição do ar, poluição radioativa, poluição sonora, etc. Estes efeitos devem estar dispostos de forma hierarquizada e devem atender peculiaridades regionais. Apesar da viabilidade ecológica, a técnica descrita 
apresenta um alto nível de dificuldades práticas de implantação e manutenção por parte de pequenos produtores rurais.

\section{Da viabilidade econômica}

Faremos uma breve descrição da economicidade da planos de manejo de rendimento sustentado, levando em consideração a teoria da economia ecológica e a análise custo/benefício ambiental.

PEARCE \& TURNER (1990), apontam três funções básicas para o meio ambiente:

a) Provedor de recursos;

b) Assimilador de dejetos;

c) Fonte de bem estar.

Estas funções mesmo não sendo transacionadas no mercado são geradoras de valores positivos, uma vez que a existência do meio ambiente é a condição necessária para o desenvolvimento econômico.

Uma das alternativas metodológicas que serve como instrumento no processo decisório é a expansão das fronteiras tradicionais da ACB que busca uma quantificação mais rigorosa entre as atividades econômicas. Esta metodologia procura elucidar os fluxos causa/efeito no funcionamento do ecossistema resultante da intervenção humana, avaliando e quantificando as transformações ambientais.

BARBIER et al. (1980), estabeleceu a equação geral do valor econômico relativo ao meio ambiente. Sua primeira parte diz que:

Valor Total do Usuário = Valor Total de Uso + Valor de Opção.

onde:

- Valor Total de Uso - valor que uma pessoa, empresa ou instituição paga por usar uma bem ambiental.

- Valor de Opção - expressão de preferência, uma disposição a pagar pela preservação do meio ambiente como um benefício potencial. É composto pelo valor atribuído pelos indivíduos no presente e no futuro.

A Segunda parte da equação diz que:

Valor Intrínseco = Valor de Existência.

Este é o valor que existe em "cada coisa", pode ser capturado através da preferência das pessoas pela não utilização de um determinado bem ambiental, por exemplo, respeito, simpatia e preocupação com o bem estar de seres não humanos. Assim, o valor econômico total é dado pela seguinte expressão: 
Valor Total Econômico = Valor Atual de Uso + Valor de Opção + Valor de Existência.

A comparação dos benefícios da preservação, medidos pelo valor econômico total, se dá entre o valor presente líquido e os benefícios de se preservar a área em questão. Assim, se:

$V L P-B P>0$ procede no desenvolvimento

$V L P-B P<0 \quad$ não procede no desenvolvimento

onde BP = Benefícios da Preservação

Assim, num plano de manejo de rendimento sustentado onde tem-se, teoricamente, a manutenção do estoque de capital natural, não se observa portanto o desenvolvimento econômico, de acordo com a conceituação da economia ecológica.

Algumas considerações sobre taxa de desconto e taxa de crescimento da floresta.

O desenvolvimento sustentado objetiva o desenvolvimento econômico e ambiental a longo prazo (PEARCE \& TURNER, 1990).

As decisões do proprietário florestal geralmente são influenciadas pela taxa de juros e pela taxa de crescimento da floresta, entre outros fatores. As interações entre as taxas desdobram-se ocasionando implicações para a sustentabilidade econômica.

Para o proprietário florestal é mais rentável colher e vender a floresta agora se a taxa de desconto excede a taxa de crescimento da floresta. Por outro lado, é mais lucrativo deixar a floresta crescer se sua taxa de crescimento excede a taxa de juros do mercado.

Se a preservação da floresta é importante, então a taxa de crescimento da floresta limita uma taxa de desconto teto para o desenvolvimento sustentado. Para uma taxa de desconto muito alta, o valor presente líquido da floresta irá cair abaixo da renda obtida com o uso alternativo da terra (ACKERMAN, 1994).

A preservação das florestas requer restrições nas taxas de desconto, e conseqüentemente reduz o crescimento econômico devido a redução na formação de capital.

Nos países em desenvolvimento, as taxas de juros são geralmente muito altas (ferramenta apreciada pelas políticas anti-inflacionárias) do que nos países desenvolvidos, refletindo com isto prêmios pelo alto risco, inflação e mercado de capitais pouco desenvolvido. Desta forma, a pressão do mercado para taxas de não sustentabilidade na exploração da floresta será maior nos países em desenvolvimento do que nos países desenvolvidos. 


\section{Da análise social}

Alguns outros obstáculos se erguem no caminho de agricultores potencialmente aptos a adotar técnicas de sustentabilidade florestal na Floresta Atlântica, a saber: política nacional a favor da agricultura em detrimento das florestas; base da tradição cultural dos agricultores, contrária ao uso de recursos florestais, que os tem como empecilho para atividade agropecuária.

A conexão é maior do que a sua aparência, pois uma vez que a terra "limpa" o agricultor passa a pagar menos impostos rurais, a receber assistência técnica, linhas de crédito, juros subsidiados e apoio na comercialização de produtos agrícolas.

A forte demanda por áreas agrícolas tem guiado o desamamento na Floresta Tropical Atlântica em Santa Catarina.

A regulamentação governamental também tem contribuído para a desmotivação dos agricultores, e na esperança de tentar deter o crescimento da devastação, criam planos de manejo sustentado profundamente detalhistas. A burocratização das autorizações eleva o custo da sua formulação, implementação e manutenção; por outro lado apresenta um alto custo também para o governo no sentido de compreendê-lo e monitorá-lo.

A dificuldade na obtenção das autorizações leva agricultores a vender a madeira a preços módicos a madeireiros que levam o produto acabado, com altos preços, para grandes centros.

Outro aspecto que não se pode deixar de citar, é a falta de incentivo à pesquisa florestal da Floresta Atlântica, e mesmo pesquisadores mais interessados possuem relativamente pouca experiência em tão complexa biodiversidade, existindo desta forma poucas áreas experimentais e demonstrativas. Aqueles agricultores potencialmente aptos a tratar a floresta de maneira sustentável esbarram na escassez da tecnologia, na incerteza de prováveis retornos e no reconhecimento dos riscos potenciais envolvidos. Além do que, muitos benefícios ambientais resultantes desta prática são desconhecidos e não têm significado econômico para estes pequenos agricultores, observando-se uma diferenciação entre os retornos privados e sociais.

\section{UM MODELO ALTERNATIVO}

O procedimento do governo tem falhado ao tentar conter a devastação na Floresta Atlântica, e tem prejudicado esforços para a promoção de manejo daquele recurso natural, como uma das formas de conter a degradação ambiental que vem se instalando.

Este segundo modelo substitui decisões individuais por decisões centralizadas nas comunidades envolvidas (GOTTFRIED et al, 1994).

Para sua implantação, a área da Floresta Tropical Atlântica deverá ser fracionada de acordo com o programa da UNESCO para a reserva da biosfera, citado por (UNICAMP, 1991). 
Assume-se que um decisor local (ou uma junta decisória), devidamente educado, possui mais sabedoria potencial para tomar decisões sobre o uso dos recursos do que um decisor que se encontra a milhares de quilômetros daquele local. Quando agricultores são educados sobre o valor dos recursos naturais, quando possuem informações tecnológicas e uma estrutura de suporte, pode-se utilizar do seu conhecimento para decidir melhor sobre o uso destes recursos. Ao mesmo tempo o governo deve desempenhar um papel de guia do processo de decisão, estabelecendo quais conseqüências servem ao interesse nacional. Devendo para tal observar três questões básicas que emergem do objetivo de se desejar um desenvolvimento sustentado:

"O que" a sociedade tenta sustentar?

"Quem" será o beneficiário?

"Quem" deve arcar com este custo?

A paisagem pode prover um grande número de bens e serviços (mantenedora da biodiversidade e da vida selvagem, reguladora de águas superficiais e outros). Por outro lado, provavelmente não se pode maximizar simultaneamente a produção de biomassa, a biodiversidade, a manutenção e outras "saídas" (bens e serviços ambientais). Provavelmente deverá ser feito um mistura com consequientes "tradeoff's". Objetivos incompatíveis deverão ser repensados.

A decisão de manter sustentável alguma função ecológica, em algum nível ajudará alguns e prejudicará outros. Aqueles que dirigem a política ambiental precisam ter clara a quem se dirige o benefício: aos camponeses ou à terra (GOTTFRIED et al., 1994).

Finalmente aqueles que produzem os benefícios ambientais de sistemas naturais não devem assumir sozinhos os custos de produzir estes serviços (perda financeira pelo não uso da área em questão). Agricultores devem ser compensados pelo custo da produção destes bens ambientais.

Existe hoje uma crescente literatura sobre custos e benefícios não monetários referente aos danos e serviços ambientais (BARBIER et al., 1980; PEARCE \& TURNER, 1990). Estes métodos de valoração baseiam-se na avaliação física, ou seja, nas alterações do meio que incidem sobre a saúde humana, perda/ganho de produtividade, etc. Apresenta-se a seguir uma breve descrição de alguns métodos afetos a planos de manejo florestal (COMUNE, 1995).

1. Mudança da Produtividade - é a medida de perda/ganho no produto total, que pode variar pelas ações do projeto. Devem ser em função, e tem grande dependência dos preços praticados no mercado.

\section{Estimativas de Custos Sociais}

2.1. Valor da Propriedade: objetiva determinar a variação de preços em uma determinada propriedade na área de abrangência do projeto, porém requer um elevado número de informações;

2.2. Diferencial de Salário: procura medir a alteração salarial da mão-deobra para que esta desempenhe suas funções em áreas deterioradas; 
2.3. Utilização de Bens de Mercado como Substitutos: a técnica utiliza, quando disponível, bens cotados no mercado que sejam substitutos próximos dos bens ambientais que estão sendo avaliados.

3. Avaliação Contigente - Conjunto de técnicas que procuram obter informações sobre a preferência de consumidores; o que estão dispostos a pagar por um benefício ou receber para tolerar o custo da degradação ambiental. Apresenta boa resposta, e é a técnica mais utilizada por economistas, porém tem como inconveniente um custo relativamente alto. Apesar disto, vem sendo utilizada para a estimativa de bens e serviços ambientais provenientes de áreas com florestas naturais. Segundo ECHEVERRIA et al (1995), o método apresenta um certo grau de dificuldade de implantação, que é feita através da aplicação de questionários. De acordo com as respostas obtidas os autores traçam o gráfico de identidade da floresta obtendo o seu valor total econômico esperado.

4. Custo de Reposição - é a estimativa dos custos necessários para repor o ativo danificado, como por exemplo, o aumento no uso de fertilizantes em decorrência da erosão do solo.

\section{RESULTADOS E CONCLUSÕES}

Trabalhos realizados até o momento têm dado especial ênfase à viabilidade econômica e a maior segurança ecológica, expressa na forma de recomposição do maciço florestal. Contudo, para uma maior planificação do uso da terra faz-se necessário a intensificação de pesquisa para a definir melhor a elasticidade na relação economia e ecologia.

As duas ciências, apesar de apresentarem faces opostas, pertencem à mesma moeda. Desgaste sofrido por uma das faces reflete inevitavelmente conseqüências na outra.

A técnica de manejo sustentado permite inclusive a classificação da floresta, em termos concretos quais áreas devem ser destinadas à produção econômica e quais devem ser preservadas. Isto porque a dita técnica resguarda em primeiro plano o aspecto ecológico secundado pelo sócio-econômico. Áreas onde o estoque de crescimento excede o estoque utilizável não há viabilidade econômica no empreendimento e devem portanto ser definidas como parques ou reservas.

No tocante ao desenvolvimento sócio-econômico de uma região, devese levar em consideração o crescimento de diversos setores da economia harmonizados com o crescimento demográfico.

Presença de cobertura vegetal não significa necessariamente a existência de floresta com valor econômico, ecológico e social. A continuidade da produção florestal com espécies de alto valor depende do estoque e da estrutura de regeneração, tanto qualitativa quanto quantitativa, desta feita o 
manejo sustentado pode assegurar a implantação de maciços com características que satisfaçam o objetivo no final de cada ciclo produtivo.

Sem dúvida, no atual estágio de estudo os maciços florestais carecem muito de informações quanto à velocidade de produção. Investigações deverão ser ampliadas neste aspecto, pois delas dependem o conhecimento da rentabilidade de cada espécie, tanto a rentabilidade econômica, ecológica ou social.

A existência, a continuidade e o crescimento da contribuição do setor florestal à economia nacional depende da política florestal e ambiental. Política esta que deverá ser embasada em critérios técnico científicos de planificação.

Enquanto que áreas remanescentes de Floresta Tropical Atlântica possuem um grande estoque de recursos renováveis e não renováveis sua população é pobre e obtêm poucos benefícios do seu rico ambiente natural que é rapidamente dilapidado. O contínuo desmatamento leva a uma maior fragmentação da floresta e ao declínio de bens e serviços ambientais sem "preço de mercado". Mais ainda, desde que a fragilidade dos solos não pode suster a produtividade e uma agricultura proveitosa, esta por si não dará as bases para as condições mínimas de qualidade de vida. A falta de cobertura florestal adequada leva ao êxodo rural (SAA/SC, 1994) e ao incremento do problema social em áreas urbanas.

Mesmo que setores do governo tenham-se utilizado de uma pesada intervenção na tentativa de regulamentar o uso dos recursos naturais, sua política agrária, e mesmo políticas florestais induzem ao desmatamento.

Entende-se que o governo deve manter uma rígida legislação contra a devastação ambiental, porém deve promover técnicas de sustentabilidade, ainda mais deve promover a organização apropriada das comunidades locais que se beneficiam do manejo de florestas a fim de promover um melhor aproveitamento de matéria-prima, estabelecendo incentivos àquela prática, e que inclui uma compensação pelo não uso da terra. Certamente as populações urbanas não podem esperar tão grande sacrifício das populações rurais. Da mesma forma camponeses devem receber uma renda pela utilização ambientalmente adequada de sua área florestal.

A política ambiental deve estar voltada para o desenvolvimento das comunidades que sobrevivem da área da Floresta Tropical Atlântica, concentrando esforços para desenvolver mercado para produtos e sub produtos florestais, no treinamento de pequenos agricultores, no desenvolvimento de técnicas de manejo que presta a assistência técnica maior credibilidade, criando programas de certificação de madeira provenientes do manejo sustentado da terra, enfim a legislação rígida por si só, e o abandono de pequenos agricultores, tem efeito oportuno à desejabilidade legal; o incremento no índice de devastação da Floresta Tropical Atlântica. 


\section{BIBLIOGRAFIA CITADA}

ACKERMAN, F. 1994 The natural rate of the forest: macroeconomic requirements for sustainable development. Amsterdan. Ecological Economics, 10: 21-26.

BARBIER, E., MARKANDIA, R. PEARCE, D. W. 1980. Enviroment sustentability and cost benefict analysis. Enviroment and Planing EEUU.

CENTRO DE PESQUISAS FLORESTAIS DA UFPR. Sistema de alarme para a região de influência de Itaipu. Curitiba, PR. p. 51.

COMUNE, A. V. 1995. Métodos de valoração. Seminário de avaliação econômica do meio ambiente. Florianópolis, SC.

UNICAMP - CONSÓRICIO MATA ATLÂNTICA, 1991. Reserva da biosfera da mata atlântica: plano de ação, referências básicas. Universidade Federal de Campinas, SP. V. 1.

ECHEVERRIA, J., HANRAHAN, M., SOLÓRZANO, R. 1995. Valuation of non priced amenities provided by biological resources within the monteverde cloud forest preserv - Costa Rica. Amsterdan. Ecological Economis. 13: 43 - 52.

FATMA - FUNDAÇÃO DE AMPARO AO MEIO AMBIENTE / SC. 1995. Tombamento da mata atlântica e seus ecossistemas associados no estado de Santa Catarina. Florianópolis. SC.

GOTTERIED, R. R., BROCKETT, C. D., DAVIS, W. C. 1994 Models of sustainable development and forest resource management in Costa Rica. Amsterdan. Ecological Economics. 9: 107 - 120.

HOSOKAWA,R. T. 1982. Manejo sustentado de florestas naturais - aspectos econômicos, ecológicos e sociais. Congresso Nacional sobre Essências Nativas. Campos do Jordão. SP. ANAIS 1465 - 1472.

KLEIN, R. M. 1978. Mapa fitogeográfico de Santa Catarina. Herbário Barbosa Rodrigues / UFSC, SC.

PEARCE, D. W., TURNER, R. K. 1990. Economics of natural resources and the enviroment. The John Hopkins University Press. Baltimmore.

SAA/SC - SECRETARIA DE ESTADO DE AGRICULTURA E ABASTECIMENTO, 1994. Manual de uso, manejo e conservação do solo. EPAGRI. Florianópolis. SC.

Gazeta Mercantil - 6/07/1999 - Jorn. Regina Scharf/SP. 